\title{
Railway Suicide in The Netherlands Lower Than Expected
}

\author{
Are Preventive Measures Effective?
}

\author{
Cornelis A. J. van Houwelingen ${ }^{1}$, Alessandro Di Bucchianico², Domien G. M. Beersma ${ }^{3}$, and \\ Ad J. F. M. Kerkhof ${ }^{4}$ \\ IIntegrated Mental Health Services Eindhoven (GGzE), The Netherlands \\ ${ }^{2}$ Department of Mathematics and Computer Science, Eindhoven University of Technology, The Netherlands \\ ${ }^{3}$ Research Unit of Chronobiology, Rijksuniversiteit Groningen, The Netherlands \\ ${ }^{4}$ Department of Clinical Psychology, Amsterdam Public Health Research Institute (APH), Vrije Universiteit Amsterdam, The Netherlands
}

\begin{abstract}
Background: Increasing rail transportation requires appropriate railway suicide preventive measures. Aims: The investigation of trends in railway suicide during 2008-2018, a period in which preventive measures were taken by Dutch railway infrastructure manager ProRail. Methods: Generalized linear regression models for railway suicide were developed for the period 1970-2007 with general suicide rate, railway traffic intensity, and a combination of these variables as regressors. Subsequently, the best-fitting model was used to investigate trends in railway suicide after 2007 by comparing in retrospect observed values with the expected outcomes of the regression model. Results: An adequate regression model for railway suicide was obtained using both general suicide rate and railway traffic intensity as regressors. Based on this model, while national suicide mortality and railway traffic increased, a distinct relative decline in railway suicides was found from 2012 onward. Conclusions: This decline of railway suicides in the Netherlands may indicate that preventive measures taken by ProRail were effective and prevented around 85 railway suicides annually, a reduction of $30 \%$.
\end{abstract}

Keywords: suicide, railroads, statistics, prevention, The Netherlands

Since the expansion of railway transport in the 19th century, our society has been confronted with the harsh reality of suicides on the tracks (Clarke, 1994). Besides lives lost, this suicide method complicates the grief of survivors and constitutes a huge burden for railway personnel and others involved (Bardon \& Mishara, 2015; Mehnert et al., 2012). Usually, thousands of travelers are directly or indirectly involved. Moreover, these incidents are highly disruptive to railway traffic. In Europe, from 2012 to 2016, there were almost 3,000 annual occurrences of railway suicide, representing $73 \%$ of all fatalities on European railways (European Union Agency for Railways, 2018). As population growth, increasing mobility needs, and strategies for reducing $\mathrm{CO}_{2}$ emissions are bound to increase rail transport volumes, more railway suicides can be expected with a concomitant increase of human suffering and disruption of services on heavily trafficked tracks. These concerns have led to the EU RESTRAIL project, which provides tools for the reduction of suicide and trespass on railway tracks (http://www.restrail.eu; Havârneanu et al., 2017), and to preventive measures in a number of European countries, Australia, and Japan (Ryan et al, 2018). In the Netherlands, railway infrastructure manager ProRail completed a first series of interventions in the course of 2007 to reduce unauthorized access to railways and the number of railway suicides. Investments in preventive safety measures were continued ever since (van der Veer, 2016).

To evaluate the impact of these preventive measures, formulating a quantitative model for the accurate description of the dynamics underlying railway suicide rates would be helpful. Such a model requires relevant variables with readily available quantitative data. In a Dutch longitudinal study covering the period 1950-2007, the railway suicide rate was seen to be related to the general suicide rate (van Houwelingen et al., 2010). Also, a slight gender difference was observed. A cross-national study on railway suicide in the Netherlands and Germany over the years 2000-2007 highlighted the importance of railway traffic intensity (van Houwelingen et al., 2013). These findings caused the authors to examine statistical models for the separate and combined influences of general suicide frequency and railway traffic intensity using data from 1970 to 2007, the period before 
preventive measures were taken in the Netherlands. The goal of this exercise was to find an appropriate regression model that would enable us to evaluate in retrospect trends from 2008 to 2018, the time preventive measures were taken. In summary, the following research questions were formulated:

1. Which regression model describes best the observed railway suicide rates in the period 1970-2007: (a) a model with general suicide rate as only regressor, (b) a model with railway traffic intensity as only regressor, or (c) a model with both regressors?

2. Does a regression model describing the relation between general suicide rates, railway suicide rates, and railway traffic intensity remain valid even if changes may have taken place over time in general and railway suicide rates? In other words, can the whole period 1970-2007 be captured in one model only?

3. Do railway suicide rates in the Netherlands in the period 2008-2018, corrected for general suicide rate and railway traffic intensity, differ from expectations based on the data from 1970 to 2007?

4. Can changes in railway suicide mortality be attributed to preventive measures taken by the railway infrastructure manager?

\section{Methods}

\section{Sample and Data Source}

Data on railway suicides in 1980-2018 were obtained from the Dutch railway infrastructure manager ProRail, which keeps records of all suicidal behavior on the national railway network, with the exception of underground, lightrail, and tram systems. Records are based on statutory investigations by the local police and coroner of every unnatural death and include suicides by jumping or lying down in front of a moving train or by deliberately crashing a car into a moving train. These records are a reliable source for the study of railway suicide, as there is a strong correspondence with the data collected by the Centraal Bureau voor de Statistiek (Statistics Netherlands, https:// cbs.nl), while having the advantage of a shorter reporting time frame (Reynders et al., 2011). The records provided by ProRail report gender in $97.9 \%$ of cases. Our database was enlarged by adding the annual frequencies of transportation suicides (overground and underground trains, unspecified) of 1970-1979 from the Centraal Bureau voor de Statistiek. The proportion of underground railway suicides in 1970-1979 is considered to be very small, as underground systems only started to function on a limited scale in two cities (Rotterdam and Amsterdam) in 1968 and 1977. The time period 1970-2007 was chosen because it provided a large enough database for the purpose of the first part of our study, while before and after this period changes had taken place in Dutch society that may have influenced the incidence of railway suicide, that is, the detoxification of domestic gas between 1963 and 1968 (Clarke \& Lester, 1989, Chapter 2), the conversion of gated level crossings to half-barrier level-crossings from 1959 to 1962 , and the realization of an array of preventive measures by ProRail from 2007 onward, as mentioned in the introduction.

ProRail provided data on the length of the national railway network and on kilometers run by trains on Dutch territory. National suicide statistics and national population figures were obtained from the Centraal Bureau voor de Statistiek. Gender was specified in all data provided by the Centraal Bureau voor de Statistiek. Annual railway suicide and general suicide rates (per 100,000 inhabitants) were calculated based on the January 1 census of the Dutch population. Nonresident railway suicides from the ProRail database were not included.

\section{Railway Traffic Intensity}

Railway traffic intensity was defined as train kilometers divided by railway length in kilometers. Train kilometers are kilometers run by national and international passenger trains and freight trains of all carriers on Dutch territory. Railway length is the number of kilometers of railway in use for scheduled passenger trains and/or freight trains, independent of the number of tracks. The number of tracks was not included as it was assumed that the number of trains passing by influences suicide opportunity at a location rather than the number of tracks.

\section{Exploratory Data Analysis}

In this section, trends in the variables of interest are explored over the period 1970-2018. Note that the formulation of the models is only based on data regarding 1970-2007. In general suicide rates increasing trends for men and women emerged between 1970 and 1984. After 1984, a gender difference was found. For men, after an initial steep decline until 1990, rates remained almost stable till an exceptional low in 2007 , followed by a steep increase in the period 2008-2013, a stabilization during 2014-2017, and a lower value in 2018. For women, rates decreased from 1985 onward to a low in 2007 and then steadily increased in the period 2008-2018 (see Figure S1 in ESM 1). Railway suicide rates for both men and women manifested increasing, almost linear, trends until 
approximately 1985 . There was no clear trend between 1985 and 1994. From 1994 to 2003, railway suicide rates for men decreased, then increased again, and stabilized after 2007, with considerable annual variations. For women, a decline was observed in the period 1995-2007, followed by an increase from 2008 onward. In 2018, values for men and women were considerably lower, though (see Figure S2 in ESM 1). The percentage of railway suicides related to general suicides increased until about 1976 for men and 1980 for women. Since then, percentages for men and women largely remained the same within margins, with the exception of an outlier for women in 1989. The percentages were seen to be slightly larger for men than for women. Railway traffic intensity showed an almost linear upward trend from a value of 35,674 train $\mathrm{km} /$ railway $\mathrm{km}$ in 1972 toward 53,333 train $\mathrm{km} /$ railway $\mathrm{km}$ in 2018.

The observed changes over time in the variables general suicide and railway suicide rate do not necessarily imply changes in the relation between these variables as captured in the model, which may remain the same (e.g., if the percentage of railway suicides in relation to all suicides remained constant).

The main conclusions from the exploratory data analysis regarding the period 1970-2007 are, therefore, as follows:

1. In this period, the relation between general suicide rates and railway suicide rates was slightly different for men and women in terms of values and course over time. By way of precaution, it is necessary to formulate separate models for men and women.

2. Overall, the ratio of railway suicides to general suicides remained stable, so that building regression models for railway suicide rates with general suicide rate as one of the regressors seems plausible.

3. Railway traffic intensity is increasing. Therefore, it seems worthwhile to investigate whether adding railway traffic intensity improves the models mentioned in 2.

\section{Statistical Modeling}

Using the exploratory data analysis as a basis, we fitted linear regression models relating railway suicide rates to general suicide rates (Model 1), to railway traffic intensity (Model 2), and to both (Model 3). We limited ourselves to data regarding 1970-2007, for reasons explained in the section Sample and data source. Rates were transformed to absolute numbers, taking into account the changes in population size, so that we could apply the generalized linear model regression framework for count data. The details of the models are described in ESM 2.
In all statistical analyses, a $p$-value of less than .05 was considered statistically significant. Diagnostics for the quasi-Poisson models performed on standardized deviance residuals, following the recommendations of McCullagh and Nelder (1991) (Chapter 12), did not reveal difficulties with the regression model assumptions. The hierarchical structure of the models enabled us to statistically test whether Model 3 is superior to Model 1 or Model 2 by using an $F$-test. We fitted separate models for men and women. All evaluations were performed with the statistical software package $\mathrm{R}$ version 4.0.3 for Windows.

\section{Investigating Trends After 2007}

We determined retrospectively whether observed railway suicide rates in each of the past years (2008-2018) were in agreement with the expected outcomes of the best-fitting regression model based on relevant data from 1970 to 2007, the period before preventive measures. In other words, we made a comparison between observed railway suicide rates and backcasted railway suicide rates.

\section{Results}

\section{Comparing Statistical Models for the Period 1970-2007}

Models were fitted as described in the section Statistical modeling. Diagnostic analysis of the separate models for men and women revealed no problems for Models 1 and 3, while Model 2, as expected, showed signs of a missing variable. The models combining men and women ("all") showed serious deficiencies, as expected from the exploratory data analysis. It was therefore decided to discontinue using these combined models, and instead to present overall results by adding up the results from the separate models for men and women.

To check for overdispersion in our data, dispersion parameters were estimated using a quasi-likelihood approach with canonical log link. The dispersion parameter values for all models ranged between 2.1 and 7.8 , indicating that Poisson regression was inappropriate. Instead, our analyses used quasi-Poisson regression models with canonical log link.

ANOVA tests using the hierarchical structure of Models 1, 2, and 3 showed that Model 3, with the inclusion of railway traffic intensity in addition to general suicide rate, is significantly better than Models 1 and 2 ( $p$-values <.008). 


\section{Trend Analysis of Railway Suicides in the Period 2008-2018}

In this section, we investigated whether the railway suicide frequencies for the period starting in 2008 differed from values expected on the basis of Model 3. With the exception of the years 2009-2011 for men and 2008 for women, the ratio of observed and expected railway suicide rates was found to be considerably smaller than 1 , meaning that the observed values were falling behind (see Table S1 in ESM 3). When converting these rates to absolute numbers, considerable differences were noticed between the observed numbers of railway suicides and the numbers expected from 2012 onward (see Table S2 in ESM 3 and Figure 1). Because of the gender effect noticed before, the assessment of the total number of railway suicides was made by obtaining separate estimates for men and women, and then adding them up. Added up, the differences between expected and observed values during the years 2012-2018 equaled 322 for men and 287 for women, respectively, with an overall difference of $30 \%$. This amounted to an average of 46 and 41 fewer railway suicides per year than expected.

\section{Discussion}

This study investigated models of the relation between general suicides, railway suicides, and railway traffic intensity over the period of 1970-2007. It was found that a model with general suicide rate and railway traffic intensity as regressors (Model 3) showed a good fit that was significantly better than models with only one of these variables. This model performed well for both men and women in spite of changes over time in the individual variables.

This best-fitting model was then used to backcast railway suicide over the period of 2008-2018, when railway suicide preventive measures were taken. The application of this model threw a new light on the relatively "stable" annual railway suicide figures from 2008 onward. Retrospectively, an unprecedented deviation of railway suicide from model expectations was observed, with much lower actual values during 2012-2018. This was surprising as general suicide rates had manifested a steep increase of 32\% between 2008 and 2016 (see Figure S1 in ESM 1).

It seems unlikely that this relative decline of railway suicides came about because the population at risk for railway suicide was unaffected by the factors associated with
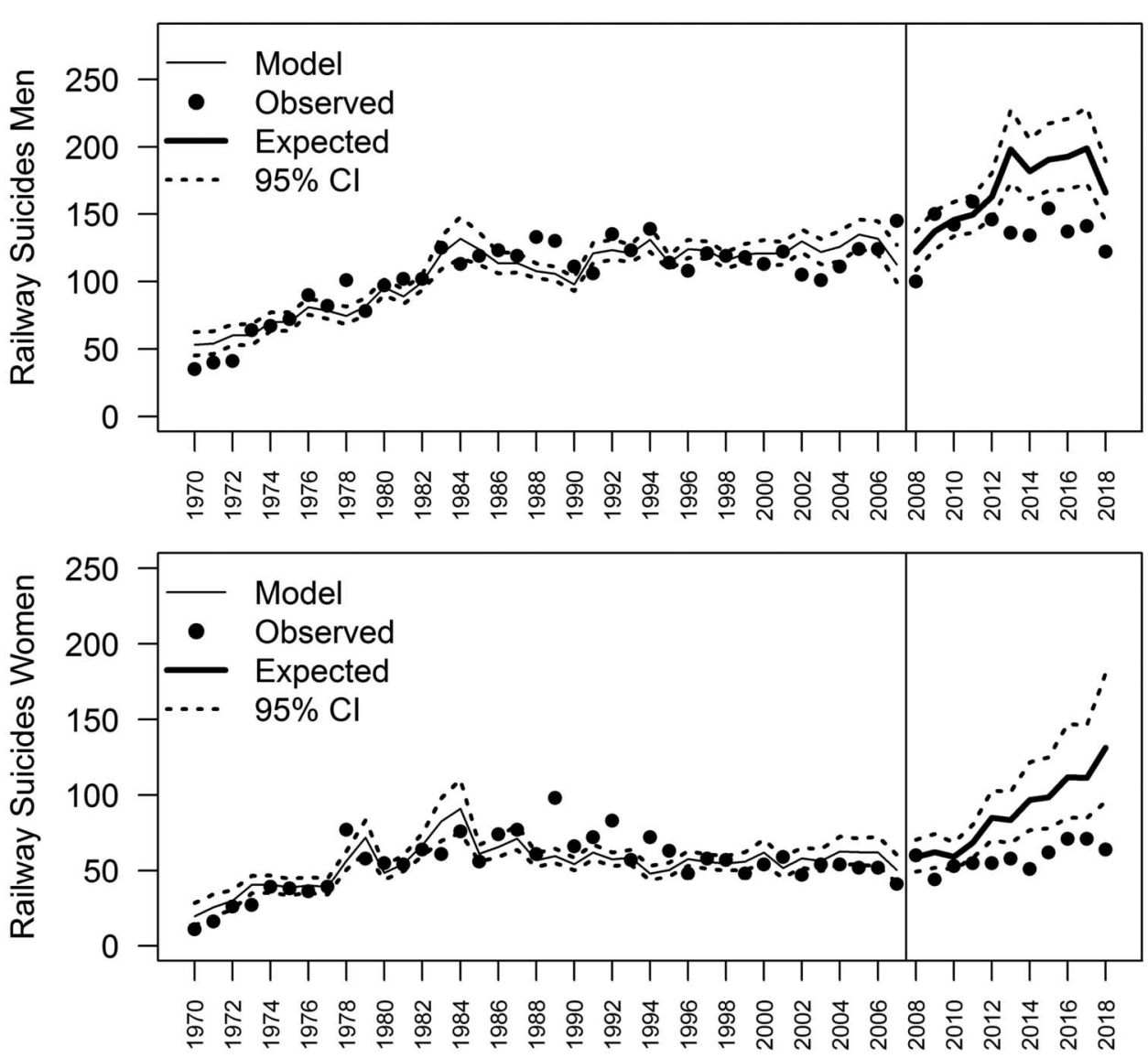

Figure 1. Railway suicides in the Netherlands: observed and fitted values (1970-2007) and observed and expected values (2008-2018). Model $=$ Model 3 with general suicide rate and railway traffic intensity as regressors. The vertical line marks the beginning of the gradual introduction of railway suicide preventive measures. 
the rise of general suicides observed after the 2008 global economic crisis (Chang et al., 2013). The likelihood of suicide was three times higher for persons affected by a severe disease, either physical or psychological during this economic crisis (Merzagora et al., 2016), and people who died by suicide on the railway were found to be more severely ill than general suicides (van Houwelingen \& Kerkhof, 2008). As the relative decline coincided with preventive measures taken by ProRail, and in the absence of alternative explanations, it seems plausible that these interventions were effective. The interventions are described in more detail in ESM 4. While the Dutch railway suicide and trespass prevention program may have been effective, it is important to note that the impact of a railway suicide prevention program in England, Scotland, and Wales launched in 2010 remained unclear (Taylor et al., 2016). The Dutch program and the UK program "Tackling Suicide on the Railways" show some similarities, but also differences. In the United Kingdom, where around $43 \%$ of railway suicides take place at stations, the majority of the UK program activities were targeted at stations, and few physical measures were included in the program (Rail Safety and Standards Board, 2013). In the Netherlands, where only about $20 \%$ of the railway suicides occur at stations (van Houwelingen et al., 2010), an array of physical measures was carried out, predominantly realized on high-risk locations outside of stations, in addition to the activities the program had in common with the UK initiative. As such, the Dutch interventions are an example of a "whole railway system approach" advocated by Ceccato and Uittenbogaard (2016), an approach encompassing parts of the railway system beyond platforms and areas near stations. Managing suicidal behavior at level crossings is difficult, though. Railway suicide prevention programs are in dire need of the introduction of advanced surveillance technology using algorithms able to recognize this type of behavior plus adequate follow-up (Mishara et al., 2016; Ryan, 2017). This applies even more to railway stations with their inherent complexity. Regions where railway suicides predominantly happen at stations may, therefore, at this moment in time, be at a disadvantage, considering the currently available technology. This may, in part, explain the different outcomes of the UK and Dutch programs.

A remaining question is why the trend break has manifested itself from 2012, while step-by-step preventive measures were taken from 2007 onward. A small rise of railway suicides due to a Werther effect related to the death of a famous German football player on November 10, 2009, and of a famous Dutch actor on October 6, 2010, may have masked the effectiveness of the preventive measures to some extent (B. Hoogcarspel, personal communication, June 19, 2018; Koburger et al., 2015; Ladwig et al., 2012). Alternative explanations are that the implementation of subsequent preventive measures only reached momentum in 2012 or that elements of the approach that were realized in 2012 were more effective than previous ones, or had a relevant add-on effect.

If the cause of the discrepancy between expected and observed values lies in fact in preventive measures, then they were highly relevant for Dutch society. The calculated number of "lives saved" from railway suicide is around 85 cases per year, which would mean a huge reduction of suffering, inhumane endings of lives, railway personnel stress, passenger discomfort, and economic costs. This amounts to $€ 8.5$ million per annum, as in the Netherlands a railway suicide incident involves $€ 100 \mathrm{k}$ of direct economic costs for carrier and railway manager together (van der Veer, 2016). It also implies a significant prevention of railway traffic interruption and a reduction of the economic cost for passengers as well.

\section{Limitations}

With the exception of gender, no other regressors were included in the models we explored that may have influenced railway suicide rates in the course of the study period. As mentioned above, media attention may have an impact on the prevalence of railway suicide. But this impact may vary according to how incidents are reported (Arendt et al., 2018; Niederkrotenthaler et al., 2010). The inability to include such factors may have limited the accuracy of our best-fitting model to some extent.

Although different age groups may manifest different trends over time (Baumert et al., 2006; Taylor et al., 2016), we chose not to include age as a variable in our models. A meaningful differentiation of age groups would result in small populations and correspondingly wide confidence intervals and jeopardize the scope of this study, which is developing a model robust enough to detect major trends.

This study does not establish a causal relation between railway preventive measures and the relative reduction of railway suicides. Nonetheless, the relationship seems plausible. Neither were the materials of this study adequate for evaluating the separate preventive measures.

\section{Conclusion}

We formulated a parsimonious model with two regressors, that is, general suicide rate and railway traffic intensity, evaluating actual railway suicides in a satisfactory manner. 
This model may help policymakers and railway infrastructure managers to critically appraise crude annual numbers of railway suicides. The model may also serve as a tool to retrospectively evaluate the impact of the 2020 economic and health crisis on railway suicide.

The discrepancy between expected and observed numbers of railway suicides since 2012, most probably related to protective measures, encourages the continuation of investments in preventive measures by the rail industry and governmental bodies. While at first sight it may be concluded that railway suicide numbers remain unchanged in spite of governmental notes and millions of Euros spent, the most likely truth is that things would have been much worse without these efforts. Even in the complex matter of railway suicide taking preventive actions seems to help.

\section{Electronic Supplementary Materials}

The electronic supplementary material is available with the online version of the article at https://doi.org/ 10.1027/0227-5910/a000792

ESM 1. Figures S1 and S2 show general suicides rates and railway suicide rates in the period 1970-2018.

ESM 2. Formulas of Models 1-3

ESM 3. Tables S1 and S2 show the values of variables after 2007 (rates and absolute numbers) of Model 3.

ESM 4. Description of preventive measures taken by ProRail

\section{References}

Arendt, F., Scherr, S., Niederkrotenthaler, T., \& Till, B. (2018). The role of language in suicide reporting: Investigating the influence of problematic suicide referents. Social Science \& Medicine, 208, 165-171. https://doi.org/10.1016/j.socscimed.2018.02.008

Bardon, C., \& Mishara, B. L. (2015). Systematic review of the impact of suicides and other critical incidents on railway personnel. Suicide and Life-Threatening Behavior, 45(6), 720-731. https:// doi.org/10.1111/sltb.12164

Baumert, J., Erazo, N., \& Ladwig, K. H. (2006). Ten-year incidence and time trends of railway suicides in Germany from 1991 to 2000. European Journal of Public Health, 16(2), 173-178. https:// doi.org/10.1093/eurpub/cki060

Ceccato, V., \& Uittenbogaard, A. (2016). Suicides in commuting railway systems: The case of Stockholm county, Sweden. Journal of Affective Disorders, 198, 206-221. https://doi.org/10. 1016/j.jad.2016.02.051

Chang, S.-S., Stuckler, D., Yip, P., \& Gunnell, D. (2013). Impact of 2008 global economic crisis on suicide: Time trend study in 54 countries. British Medical Journal, 347, f5239. https://doi.org/ 10.1136/bmj.f5239
Clarke, M. (1994). Railway suicide in England and Wales, 1850-1949. Social Science \& Medicine, 38(3), 401-407. https://doi.org/10. 1016/0277-9536(94)90439-1

Clarke, R. V., \& Lester, D. (1989). Suicide: Closing the exits. Springer. European Union Agency for Railways. (2018). Report on railway safety and interoperability in the EU, 2018. https://doi.org/10. 2821/49834

Havârneanu, G. M., Burkhardt, J.-M., \& Silla, A. (2017). Optimizing suicide and trespass prevention on railways: A problem-solving model from the RESTRAIL project. International Journal of Injury Control and Safety Promotion, 24(4), 469-486. https://doi.org/ 10.1080/17457300.2016.1232275

Koburger, N., Mergl, R., Rummel-Kluge, C., Ibelshäuser, A., Meise, U., Postuvan, V., Roskar, S., Székely, A., Ditta Tóth, M., van der Feltz-Cornelis, C., \& Hegerl, U. (2015). Celebrity suicide on the railway network: Can one case trigger international effects? Journal of Affective Disorder, 185, 38-46. https://doi.org/10. 1016/j.jad.2015.06.037

Ladwig, K. H., Kunrath, S., Lukaschek, K., \& Baumert, J. (2012). The railway suicide death of a famous German football player: Impact on the subsequent frequency of railway suicide acts in Germany. Journal of Affective Disorders, 136(1-2), 194-198. https://doi.org/10.1016/j.jad.2011.09.044

McCullagh, P., \& Nelder, J. A. (1991). Generalized linear models (2nd ed.). Chapman and Hall.

Mehnert, A., Nanninga, I., Fauth, M., \& Schäfer, I. (2012). Course and predictors of posttraumatic stress among male train drivers after the experience of "person under the train" incidents. Journal of Psychosomatic Research, 73(3), 191-196. https://doi. org/10.1016/j.jpsychores.2012.06.007

Merzagora, I., Mugellini, G., Amadasi, A., \& Travaini, G. (2016). Suicide risk and the economic crisis: An exploratory analysis of the case of milan. PLoS One, 11(12), e0166244. https://doi.org/10. 1371/journal.pone.0166244

Mishara, B. L., Bardon, C., \& Dupont, S. (2016). Can CCTV identify people in public transit stations who are at risk of attempting suicide? An analysis of CCTV video recordings of attempters and a comparative investigation. BMC Public Health, 16(1), 1245. https://doi.org/10.1186/s12889-016-3888-x

Niederkrotenthaler, T., Voracek, M., Herberth, A., Till, B., Strauss, M., Etzersdorfer, E., Eisenwort, B., \& Sonneck, G. (2010). Role of media reports in completed and prevented suicide: Werther $\mathrm{V}$. Papageno effects. British Journal of Psychiatry, 197(3), 234-243. https://doi.org/10.1192/bjp.bp.109.074633

Reynders, A., Scheerder, G., \& van Audenhove, C. (2011). The reliability of suicide rates: An analysis of railway suicides from two sources in fifteen European countries. Journal of Affective Disorders, 131, 120-127. https://doi.org/10.1016/j.jad.2010.11.003

RSSB. (2013). Improving suicide prevention measures on the rail network in Great Britain (T845). https://www.rssb.co.uk/ research-catalogue/Catalogueltem/T845

Ryan, B. (2017). Developing a framework of behaviours before suicides at railway locations. Ergonomics, 61(5), 605-626. https://doi.org/10.1080/00140139.2017.1401124

Ryan, B., Kallberg, V.-P., Rådbo, H., Havârneanu, G. M., Silla, A., Lukaschek, K., Burkhardt, J.-M., Bruyelle, J.-L., El-Koursi, E.-M., Beurskens, E., \& Hedqvist, M. (2018). Collecting evidence from distributed sources to evaluate railway suicide and trespass prevention measures. Ergonomics, 61(11), 1433-1453. https://doi. org/10.1080/00140139.2018.1485970

Taylor, A. K., Knipe, D. W., \& Thomas, K. H. (2016). Railway suicide in England and Wales 2000-2013: A time-trends analysis. BMC Public Health, 16, 270. https://doi.org/10.1186/s12889-0162944-x 
van der Veer, A. (2016). Evaluatie programma suicidepreventie ProRail 2010-2015 (EDMS-\#3898484) [Evaluation of the ProRail suicide prevention program 2010-2015]. ProRail.

van Houwelingen, C., Baumert, J., Kerkhof, A., Beersma, D., \& Ladwig, K.-H. (2013). Train suicide mortality and availability of trains: A tale of two countries. Psychiatry Research, 209(3), 466-470. https://doi.org/10.1016/j.psychres.2012.12.026

van Houwelingen, C. A. J., \& Kerkhof, A. J. F. M. (2008). Mental healthcare status and psychiatric diagnoses of train suicides. Journal of Affective Disorders, 107(1-3), 281-284. https://doi.org/ 10.1016/j.jad.2007.08.024

van Houwelingen, C. A. J., Kerkhof, A. J. F. M., \& Beersma, D. G. M. (2010). Train suicides in The Netherlands. Journal of Affective Disorders, 127(1-3), 281-286. https://doi.org/10.1016/j.jad.2010. 06.005

\section{History}

Received July 1, 2020

Revision received January 21, 2021

Accepted January 31, 2021

Published online May 18, 2021

\section{Conflict of Interest}

The authors report no conflict of interest.

\section{Funding}

This study was not funded. ProRail supplied data for the study but were not involved in its design, conduct, analysis, or reporting. Once the paper was accepted for publication, ProRail contributed the open access publication fee.

\section{ORCID}

Cornelis A. J. van Houwelingen

(D) https://orcid.org/0000-0002-1034-9156

\section{Cornelis A. J. van Houwelingen}

Integrated Mental Health Services Eindhoven (GGzE)

Dr. Poletlaan 39, Room DP 3901

5626 ND Eindhoven

The Netherlands

cajvhou@gmail.com

Cornelis A. J. van Houwelingen, MD, PhD, is a psychiatric consultant at the Integrated Mental Health Services Eindhoven (GGzE) in The Netherlands. In addition, he conducts research on railway suicide.

Alessandro Di Bucchianico, PhD, is an associate professor of statistics in the Department of Mathematics and Computer Science at Eindhoven University of Technology, The Netherlands. He participates in applied research projects with companies and governmental organizations. His main research interest is the statistical analysis of dynamic data, particularly in statistical methods to detect trends or changes over time.

Domien G. M. Beersma, PhD, is professor emeritus of chronobiology at the research institute GELIFES of the University of Groningen, The Netherlands. He participates in experimental studies and theoretical modeling of observed behavioral rhythms, with a focus on daily and annual patterns. His areas of interest include suicidal behavior.

Ad J. F. M. Kerkhof, PhD, is professor emeritus of clinical psychology and suicide prevention at the Vrije Universiteit in Amsterdam, The Netherlands. He conducts research into the epidemiology of suicide and attempted suicide, suicide in prisons, railway suicides, suicides in mental health care, the assessment of suicidal risk in adolescents, and online self-help intervention for suicidal thoughts. 